\title{
Het toetsen van de werking van de interne beheersingsomgeving door de Raad van Commissarissen
}

\section{Oscar van Leeuwen en Philip Wallage}

SAMENVATTING In dit artikel wordt een verkenning uitgevoerd naar de taak en verantwoordelijkheden van commissarissen bij het beoordelen van de control environment (interne beheersingsomgeving). De auteurs betogen dat het toetsen van de werking van de control environment tot de toezichthoudende taak van de commissarissen behoort. De code Tabaksblat en de Amerikaanse regelgeving geven geen concrete aanwijzingen aan commissarissen op welke wijze de interne beheersingsomgeving getoetst kan worden. Zowel de Nederlandse als de Amerikaanse regelgeving zijn naar de mening van de auteurs onvoldoende concreet om management override en als gevolg daarvan schandalen zoals Enron, Worldcom en Satyam te voorkomen. Zij doen in dit artikel daarom enkele suggesties op welke wijze commissarissen de beoordeling van de interne beheersingsomgeving zouden kunnen uitvoeren. Dit artikel is een vervolg op het artikel Het evalueren van de interne beheersomgeving. Een onderbelicht thema. (Van Leeuwen en Wallage, 2010).

\section{RELEVANTIE VOOR DE PRAKTIJK Dit artikel doet een aantal concrete aanbevelingen} over de wijze waarop toezichthouders de opzet en werking van de control environment zouden moeten toetsen. Door het toepassen deze aanbevelingen kan het gevaar voor management override aanzienlijkk gereduceerd worden.

\footnotetext{
1 Inleiding

Interne beheersing van financiële verslaggeving (internal control over financial reporting) wordt in de context van corporate governance veelal bezien vanuit het Amerikaanse COSO-model. In een eerder artikel (Van Leeuwen en Wallage, 2010) is ingegaan op de rol van het management bij het beoordelen van een belangrijk element uit dit model: de zogenaamde control environment of interne beheersingsomgeving. Hierin werd geconcludeerd dat het management een goede evaluatie van zowel de opzet als werking van de interne beheersingsomgeving dient uit te voeren, aangezien de effectiviteit van de interne beheersingsomgeving een belangrijke factor is voor het al of niet verstrekken van betrouwbare informatie.
}

Het management van een organisatie beïnvloedt echter niet alleen het gedrag binnen de interne beheersingsomgeving, maar is zelf ook onderdeel van deze beheersingsomgeving. Bij de grote financiële schandalen van het laatste decennium (zoals Enron, Worldcom en Satyam) speelde het management (respectievelijk Lay, Ebbers en Raju) zelf een belangrijke rol die uiteindelijk leidde tot onjuiste informatieverstrekking aan de voornaamste stakeholders van de organisatie (Beasley e.a., 2010). Het management is immers zelf in staat het stelsel van interne beheersing te doorbreken door misbruik te maken van de eigen positie. $\mathrm{Bij} 80$ procent van de rapportagefraudes is het management dan ook betrokken (Peecher et al., 2007). In geval van een opzettelijke doorbreking van de functiescheidingen leidend tot onjuiste informatie in de jaarrekening is sprake van fraude. Hiervan was onder meer sprake bij Satyam. De volgende quote uit de brief van Ramalinga Raju (CEO), die de interne beheersing doorbrak in een poging de onderneming te redden, is illustratief. Raju (2009) maakte op de volgende wijze de fraude publiekelijk:

'The gap in the Balance Sheet has arisen purely on account of inflated profits over a period of last several years (....). What started as a marginal gap between actual operating profit and the one reflected in the books of accounts continued to grow over the years. It has attained unmanageable proportions as the size of company operations grew significantly (...). The differential in the real profits and the one reflected in the books was further accentuated by the fact that the company had to carry additional resources and assets to justify higher level of operations - thereby significantly increasing the costs. Every attempt made to eliminate the gap failed. As the promoters held a small percentage of equity, the concern was that poor performance would result in a take-over, thereby exposing the gap. It was like riding a tiger, not knowing how to get off without being eaten.' 
Uit het onderzoek van ACFE (2010) blijkt in circa 60 procent van alle gevallen van occupational fraud (het gebruik maken van je positie in de organisatie om jezelf persoonlijk te verrijken door misbruik te maken van de hulpmiddelen van een organisatie) het management of een bestuurder betrokken te zijn.

In het geval van een slechte interne beheersingsomgeving (in het bijzonder door een verkeerd gedrag van het top management: tone-at-the-top) is het risico van het doorbreken van interne beheersingsmaatregelen door het management groot. Dit roept de vraag op wat de rol is van de Raad van Commissarissen ( $\mathrm{RvC}$ ) bij het beoordelen van de interne beheersingsomgeving. De RvC houdt onder meer toezicht op het functioneren van de interne beheersing (inclusief interne beheersingsomgeving).

Wij richten ons in dit artikel op organisaties die een $\mathrm{RvC}$ hebben ${ }^{1}$. Het artikel is ook van toepassing op Raden van Toezicht met een vergelijkbare rol als de RvC. Centraal staat de vraag wat de taak en verantwoordelijkheid van toezichthouders is bij het beoordelen van de interne beheersingsomgeving. Wij richten ons hierbij met name op het risico van management override, aangezien juist ten aanzien van dit aspect van de betrouwbaarheid van de financiële rapportages naar onze mening door de $\mathrm{RvC}$ een actieve (toetsende) rol moet worden vervuld (paragraaf 2). Voor het beantwoorden van deze vraag baseren wij ons in paragraaf 3 op de agency theory, aangezien de $\mathrm{RvC}$ een monitorrol speelt in de relatie tussen de principaal (aandeelhouder) en de agent (bestuurder). Daarnaast gaan wij na in hoeverre evaluatie van de interne beheersingsomgeving door de $\mathrm{RvC}$ vereist is volgens Nederlandse en Amerikaanse wetgeving (paragraaf 4). Tenslotte doen wij in paragraaf 5 een aantal suggesties over hoe een evaluatie van de interne beheersingsomgeving door toezichthouders (commissarissen) praktisch kan worden uitgevoerd.

\section{De interne beheersingsomgeving en het risico van management override}

De interne beheersingsomgeving vormt de basis voor het goed functioneren van het totale beheersingskader. Deze omgeving bestaat uit de binnen de organisatie werkzame personen met elk hun eigen integriteit, waarden en normen en vormt zodoende de cultuur waarbinnen medewerkers hun activiteiten uitvoeren (COSO, 1992). De interne beheersingsomgeving wordt vormgegeven door het management van de organisatie. Het management heeft een eigen houding ten aanzien van het nemen van risico's en bedt deze in de cultuur van de organisatie in. Daarnaast structureert het management de organisatie, verdeelt de taken en verantwoordelijkheden en implementeert verschillende regels en processen waar de werknemers van de organisatie zich aan dienen te houden. Voorts trekt het management de juiste werknemers aan en zorgt dat deze zich gedragen overeenkomstig de eisen die het management stelt. Het management vervult hierbij een voorbeeldfunctie. De door hen neergezette zogenaamde tone-atthe-top vervult daarbij een cruciale rol.

Inherent aan de rol van het management is het beïnvloeden van het gedrag van de werknemers om de organisatiedoelstellingen te bereiken. Daarnaast maakt het management zelf ook onderdeel uit van de interne beheersingsomgeving. Bij de al genoemde financiële schandalen speelde het management zelf een belangrijke rol die uiteindelijk leidde tot onjuiste informatieverstrekking aan de voornaamste stakeholders van de organisatie ${ }^{2}$. Het management is immers zelf in staat het stelsel van interne beheersing te doorbreken. Denk hierbij aan het doorbreken van de door het management zelf aangebrachte controletechnische functiescheidingen (tegengestelde belangen), en het negeren van de voor het management uitgevoerde verbands- en detailcontroles en cijferbeoordelingen. In het COSOrapport wordt dit gevaar angeduid met de term management override. De positie die het management in de organisatie inneemt zorgt er qualitate qua voor dat dit risico altijd aanwezig is. Het COSO-rapport geeft echter niet aan hoe dit risico kan worden beheerst. De literatuur op het gebied van interne beheersing richt zich met name op de maatregelen die ten behoeve van de leiding worden uitgevoerd. Als gevolg hiervan zijn weinig oplossingen voor het risico van management override te vinden. De kern van de oplossing ligt ons inziens in de rol die de toezichthouders van een organisatie $(\mathrm{RvC})$ vervullen. $\mathrm{Zij}$ moeten in het kader van hun toezichthoudende rol naar onze mening expliciet vaststellen dat er geen sprake is van management override. Wij baseren ons hiervoor mede op de agency theorie die in de volgende paragraaf zal worden behandeld. Bij het uitoefenen van deze rol zal de $\mathrm{RvC}$ zowel naar de opzet als de goede werking van de interne beheersingsomgeving moeten kijken. De RvC vervult hier derhalve een toetsende rol.

\section{Agency theorie en de Raad van Commissarissen}

Om de taak en verantwoordelijkheid van de RvC te verklaren verwijzen wij naar de agency theorie. Hiervan wordt veelvuldig gebruik gemaakt om de vraag naar toezicht en controle te verklaren (Dassen, 1989; Wallage, 1993). Er wordt uitgegaan van een belangentegenstelling tussen agent en principaal. Aandeelhouders (principalen) hebben minder informatie dan de door hen aangestelde directie van de organisatie (agenten). Bovendien hebben de agenten dikwijls belang bij het verstrekken van te roos- 
kleurige informatie. Onderwerpen als informatieasymmetrie en moral hazard ${ }^{3}$ spelen daarom een grote rol bij de vraag van de principalen (aandeelhouders) aan onafhankelijk deskundigen (de accountants) om de betrouwbaarheid van verantwoordingsinformatie van de agenten (management) te controleren.

Stakeholders (en in het bijzonder aandeelhouders ${ }^{4}$ ) laten naast externe accountantscontrole op hun agenten om vergelijkbare redenen ook toezicht op hun organisatie uitoefenen door commissarissen. De taak van de $\mathrm{RvC}_{\mathrm{V}}$ is wettelijk geregeld. Deze functie laat zich naar onze mening goed verklaren door de agency theorie. Centraal staan hierbij de onafhankelijke rol ten opzichte van de agent en voldoende kennis om het functioneren van de agent te kunnen beoordelen. In het verlengde hiervan zijn de belangrijkste elementen van de functievervulling van de commissaris in de volgende tabel weergegeven:

Als wij kijken naar de functie en positie van de $\mathrm{RvC}$ lijkt deze echter op voorhand met vergelijkbare problemen te kampen als de aandeelhouders: ook in de rolverdeling tussen directie en toezichthouder is sprake van informatieasymmetrie. De RvC heeft echter de taak om (namens de stakeholders) deze informatieasymmetrie te reduceren door voldoende toezicht uit te oefenen. Daarnaast moet de RvC alert zijn op het mogelijke optreden van moral hazard.

\section{Beoordelen door toezichthouders van de (interne) beheersingsomgeving volgens codes en wetgeving}

Onderstaand volgt een overzicht van de beoordeling van de interne beheersingsomgeving en in het bijzonder de taak en verantwoordelijkheden van toezichthouders daarbij, zoals deze volgen uit de Nederlandse Corporate Governance Code en de Amerikaanse Sarbanes Oxley wetgeving. ${ }^{5}$

\subsection{De Nederlandse situatie}

De in de Nederlandse wetgeving verankerde Code Tabaksblat (2003) vereist in bepaling II.1.4 dat het bestuur in het jaarverslag verklaart dat het interne beheersingssysteem adequaat en effectief is en geeft een duidelijke onderbouwing hiervan. Ook rapporteert het bestuur over de werking van het interne risicobeheersings- en controlesysteem in het boekjaar.

Vanwege de behoefte aan een verklaring omtrent beheersing van verslaggevingsrisico's dient het bestuur volgens de code Tabaksblat in het jaarverslag te verklaren dat de interne risicobeheersings- en controlesystemen een redelijke mate van zekerheid geven dat de financiële verslaggeving geen onjuistheden van materieel belang bevat en dat de risicobeheersings- en controlesystemen in het verslagjaar naar behoren hebben gewerkt. Het bestuur geeft hiervan een duidelijke onderbouwing (2008, II.1.5). De Code verstrekt geen nadere aanwijzingen. Wel wordt geadviseerd om gebruik te maken van een algemeen aanvaard raamwerk, waarbij naar COSO wordt verwezen. Ondanks het ontbreken van algemeen aanvaarde methoden en technieken om bedrijfsrisico's te evalueren (Van Leeuwen en Wallage, 2010), blijkt uit het monitoringonderzoek over 2009 dat deze Best Practice Bepaling goed is nageleefd (Commissie Corporate Governance, Monitoring Commissie, 2010, p. 22). ${ }^{6}$

Onderstaand wordt de taak van de RvC bij het beoordelen van de interne beheersing nader toegelicht.

De raad van commissarissen bespreekt in ieder geval eenmaal per jaar de uitkomsten van de beoordeling door het bestuur van de opzet en werking van de interne risicobeheersings- en controlesystemen, alsmede eventuele significante wijzigingen hierin. Van het houden van de besprekingen wordt melding gemaakt in het verslag van de raad van commissarissen. De auditcommissie richt zich in ieder geval op het toezicht op het bestuur ten aanzien van:

Tabel 1

\begin{tabular}{|l|l|}
\hline \multicolumn{2}{|l|}{ Commissaris } \\
\hline Functie & Toezichthouder $^{7}$ \\
\hline Object & $\begin{array}{l}\text { Brede scope: } \\
\text { Toezicht houden op de directie in al haar facetten (strategie, risico's, performance, controls, enz) (BW2) }\end{array}$ \\
\hline Benoeming & Door de Algemene Vergadering van Aandeelhouders (AvA) op voordracht van de Ondernemingsraad ${ }^{8}$. \\
\hline Deskundigheden & $\begin{array}{l}\text { Divers: bestuurlijke ervaring, deskundigheid om hoofdlijnen van het totale beleid te beoordelen, specifieke deskundigheden om } \\
\text { specifieke taak te vervullen. } \\
\text { In het Audit committee (een subcommissie van de RvC) zit minimaal één persoon met relevante kennis en ervaring opgedaan op } \\
\text { financieel administratief/accounting gebied (bij beurs- of andere grote vennootschappen) }\end{array}$ \\
\hline Onafhankelijkheid & Op maximaal één na dienen alle leden van de RvC volgens de code Tabaksblat (III.2.2) onafhankelijk te zijn. \\
\hline Communicatie & Verslag van Commissarissen, en verantwoording afleggen over toezichtactiviteiten op de AvA (Code Tabaksblat, 2003). \\
\hline
\end{tabular}


a) de werking van de interne risicobeheersings- en controlesystemen, waaronder het toezicht op de naleving van de relevante wet- en regelgeving en het toezicht op de werking van gedragscodes;

b) de financiële informatieverschaffing door de vennootschap (keuze van accounting policies, toepassing en beoordeling van effecten van nieuwe regels, inzicht in de behandeling van schattingsposten in de jaarrekening, prognoses, werk van in- en externe accountants terzake, etc)..$^{10}$ (Code Tabaksblat, 2003)

Over de rol van $\mathrm{RvC}$ (en meer specifiek van de auditcommissie) bij het beoordelen van de interne beheersingsomgeving worden door Tabaksblat geen uitspraken gedaan. Gezien het eerder genoemde gevaar van management override is dit ons inziens een onderbelicht thema.

\subsection{De situatie in de Verenigde Staten}

In de Verenigde Staten wordt door Sectie 404 van de Sarbanes Oxley wet (2002) een verklaring van het management over de effectiviteit van het interne beheersingssysteem vereist met betrekking tot financiële rapportage. De effectiviteit betreft zowel de opzet als de werking. Opvallend genoeg wordt de interne beheersingsomgeving in de guidance voor het management niet afzonderlijk benoemd (SEC, 2003). Om de wijze waarop dit ingevuld moet worden verder te verduidelijken is in 2007 nadere guidance verschenen (SEC, $2007^{11}$ ). In deze guidance wordt opmerkelijk weinig aandacht besteed aan de interne beheersingsomgeving als onderdeel van zogenaamde entity level controls. Deze controls hebben een indirect effect op de kans dat een afwijking tijdig wordt voorkomen of ontdekt (SEC, 2007, p. 18). Zij hebben invloed op andere controls maar genereren onvoldoende bewijskracht om financiële verslaggevingsrisico's te beheersen. Wel kan de relatieve sterkte/ zwakte van de interne beheersingsomgeving de inschatting van de werking van andere beheersingsmaatregelen (risk of control failure) door het management beïnvloeden (SEC, 2007, p. 22).

Wel heeft het American Institute of Certified Public Accountants (AICPA) in 2005 guidance uitgebracht voor Audit committees om het risico van frauduleuze financiële rapportage als gevolg van management override te voorkomen respectievelijk te ontdekken. De volgende zes acties om het risico van management override van interne beheersing te adresseren zijn hierin genoemd:

1. het handhaven van een sceptische houding;

2. het vergroten van de kennis van de organisatie;

3. brainstorming om fraude risico's te onderkennen;

4. gebruikmaking van de gedragscode om de financiële rapportagecultuur te beoordelen;
5. cultiveren van een klokkenluidersregeling;

6. het ontwikkelen van een breed informatie- en feedbacknetwerk.

\section{Samenvattend}

Over het beoordelen van de interne beheersingsomgeving door de $\mathrm{RvC}$ wordt zowel in Nederland als in de Verenigde Staten geen uitspraak gedaan. Naar onze mening is dit gezien het gevaar van management override een onderbelicht thema. In de volgende paragraaf werken wij daarom uit op welke wijze toezichthouders de werking van de interne beheersingsomgeving kunnen toetsen.

\section{Op welke wijze kan de RvC de opzet en werking van de interne beheersingsomgeving vaststellen?}

Hoewel de regelgeving op het vlak van het toetsen van de interne beheersingsomgeving onvoldoende concreet is ten aanzien van de eisen die worden gesteld aan de toezichthouders (paragraaf 4), zal naar onze mening wel een toets namens de stakeholders (de agenten) door de toezichthouders moeten worden uitgevoerd om verdere schandalen in de toekomst zo veel mogelijk te voorkomen. Daarbij komt uiteraard de vraag op, hoe een dergelijke toets het best kan worden uitgevoerd.

De RvC en vooral het audit committee zou bij het evalueren van de interne beheersingsomgeving een belangrijke rol moeten spelen. Zoals aangegeven heeft het American Institute of Public Accountants (AICPA) in 2005 op dit vlak guidance uitgebracht. De door hen aangeven acties om het risico van management override van interne beheersing te adresseren zijn in de hieronder beschreven aanpak verwerkt. De eerste vraag die de $\mathrm{RvC}$ zal stellen is een verklaring van het management dat het management zowel de opzet als de werking van de interne beheersingsomgeving getoetst heeft. Feitelijk is het vragen door de toezichthouders om een dergelijke verklaring van het management vragen naar een vorm van zelfcontrole van het management. De RvC zal deze verklaring met het management willen bespreken. Omdat een dergelijke zelfcontrole onvoldoende waarborgen biedt zal de RvC daarom ook kennis willen nemen van de uit deze evaluatie voortvloeiende rapportage en van de werkzaamheden die ten grondslag hebben gelegen aan het maken van de rapportage. Hiermee vult de RvC één van de zes door de AICPA genoemde activiteiten in: het vergroten van de kennis van de organisatie.

Om te komen tot de gevraagde verklaring kan het management gebruik maken van de COSO-vragenlijst voor de interne beheersingsomgeving (Van Leeuwen en Wallage, 2010). De Sarbanes-Oxley wetgeving (SOx, 2002) aanvaardt het gebruik van het COSO-model, terwijl ook in de code Tabaksblat (2003) naar COSO wordt verwezen. Het COSOmodel verdient echter de nodige aanpassingen om de effec- 
tiviteit van de interne beheersingsomgeving goed te kunnen evalueren (Van Leeuwen en Wallage 2010). Hierbij moet steeds in gedachten worden gehouden dat een belangrijk doel van COSO is een interne beheersingsomgeving te creëren die leidt tot betrouwbare financiële verslaggeving die in overeenstemming is met wet- en regelgeving. De RvC zal om de beheersingsomgeving te kunnen toetsen zowel aandacht moeten besteden aan de opzet als de werking van de beheersingsomgeving.

\subsection{De opzet van de interne beheersingsomgeving}

Aangezien de vragen zoals COSO die stelt geen norm bevatten voor wat nu een goede en wat een slechte interne beheersingsomgeving is, zal in de specifieke bedrijfssituatie een norm moeten worden bepaald. Dit betekent dat voor elke organisatie het management (en ten aanzien van de COSO-vragen die betrekking hebben op het management de toezichthouder) per te beantwoorden vraag expliciet een norm moet bepalen waartegen de interne beheersingsomgeving gemeten kan worden. Een dergelijke norm kan mede op basis van meerjarige ervaringen worden ontwikkeld. Van belang is dat deze normen binnen de organisatie transparant zijn. De meeste grote organisaties hebben een gedragscode ontwikkeld die aangeeft dat ongewenst gedrag niet getolereerd wordt.

Om tot een goed afgewogen beeld te komen, zou niet alleen het management zelf de (aangepaste) COSO-vragen moeten beantwoorden maar ook een subset van de overige medewerkers van de organisatie. Daarbij moet uiteraard aandacht worden besteed aan eventuele verschillen in beantwoording door verschillende participanten in de organisatie en de betekenis van deze verschillen in beantwoording. Door zelf een actieve rol te vervullen bij het bespreken van de vragenlijsten ontwikkelt de $\mathrm{RvC}$ tevens een breed informatie- en feedbacknetwerk (één van de zes door de AICPA aanbevolen activiteiten).

$\mathrm{De} \mathrm{RvC}$ doet er goed aan in dit kader ook aandacht te besteden aan de zogenaamde tone-at-the-top van de organisatie. Een betere tone-at-the-top resulteert namelijk in minder problemen op het gebied van betrouwbaarheid van de externe rapportages (Hunton e.a., 2011). Hierbij gaat het bij tone-at-the-top om:

- het gedrag van het topmanagement op het gebied van het vastleggen van de effectiviteit van de interne betrouwbaarheidsmaatregelen;

- het ethisch gehalte van besluitvorming binnen de organisatie;

- de mate van agressiviteit waarmee het management de gestelde doelen wil behalen of overtreffen.

Uiteraard neemt de $\mathrm{RvC}$ ook kennis van constateringen van in- en externe accountants op het vlak van de interne beheersomgeving.

\subsection{De werking van de interne beheersingsomgeving}

Het is bij de evaluatie van de interne beheersingsomgeving noodzakelijk dat de beoordeling op een transparante wijze wordt uitgevoerd. Dit vereist dat niet alleen de conclusie toetsbaar is, maar ook dat het uitgevoerde proces en bijbehorende overwegingen om te komen tot een oordeel, transparant en toetsbaar zijn. Het gaat hierbij onder meer om het kunnen toetsen van de overwegingen die betrekking hebben op dilemma's waarvoor het management zich ten aanzien van de interne beheersingsomgeving gesteld zag.

Als het antwoord op bijvoorbeeld de vraag 'Is er voldoende zicht op het gedrag van mensen ten aanzien van de betrouwbaarheid van informatie?' bevestigend is, dan moet dit niet alleen in opzet zo zijn, maar moet ook worden vastgesteld hoe dit toezicht op de betrouwbaarheid van de informatie dan is uitgevoerd en tot welke conclusies dit geleid heeft.

Soms is het vaststellen van de werking eenvoudig. Bijvoorbeeld bij de vraag naar de rapportagefrequentie. Er is eenvoudig vast te stellen hoe vaak een rapportage verstrekt wordt.

Maar soms is het vaststellen van de werking bepaald niet eenvoudig. Hoe meet je bijvoorbeeld integriteit. Zijn wij als (management) integer? Op welke aspecten? Aan wie vraag je dat dan allemaal? Hoe weeg je verschillende uitkomsten? Hoe moet een toezichthouder het antwoord van het management vervolgens wegen? Het management zal immers zeer waarschijnlijk niet van zichzelf zeggen dat ze niet integer omgaan met de betrouwbaarheid van de informatieverzorging. Het minste wat het management kan doen is in een vergadering bespreken of er aanwijzingen zijn dat één van de vragen niet op de norm scoort. De RvC kan dan vervolgens kennis nemen van de vergaderverslagen waarbij de $\mathrm{RvC}$ zich ervan bewust moet zijn dat de notulist zeer waarschijnlijk zelf aan het management rapporteert. De RvC doet er daarom goed aan het management hierover actief te bevragen.

Het management kan zelf bij het beoordelen van de werking van de interne beheersingsomgeving onder meer gebruik maken van de volgende instrumenten:

a. Het ondertekenen van een Letter of Representation (LOR), waarin expliciet de juistheid van de verantwoordingsinformatie in combinatie met de werking van de interne beheersingsomgeving wordt getoetst. Hiermee wordt het probleem van het vaststellen van de goede werking van de interne beheersingsomgeving (deels) gedelegeerd. Het risico van bias door het tekenende (lagere) management is hierbij uiteraard anwezig, aangezien dit in feite een vorm van zelfcontrole door het (lagere) management betreft. Een ander risico van een dergelijke 'zelfevaluatie' is het risico dat het management niet van alle feiten en gebeurtenissen op de hoogte 
is. $\mathrm{De} \mathrm{RvC}$ dient in elk geval kritisch met het hogere management te bespreken in hoeverre de handtekeningen door het lagere management terecht gezet zijn (professioneel kritische houding van de $\mathrm{RvC}$ ). Tevens kan de $\mathrm{RvC}_{\mathrm{C}}$ zelf enkele gesprekken voeren met het tweedelijnsmanagement aan de hand van de vragenlijsten en de van het management ontvangen rapportages om zo een gevoel te krijgen bij de rol van de directie binnen de interne beheersingsomgeving.

b. Een afzonderlijke functionaris (eventueel een daarin gespecialiseerde eigen medewerker of externe functionaris) de werking van de interne beheersingsomgeving laten toetsen door het kennisnemen van verslagen en conclusies, het houden van interviews en het uitvoeren van enquêtes. Indien bij de desbetreffende organisatie sprake is van een Interne accountantsdienst (IAD) is dit typisch een taak die door de IAD zou kunnen worden uitgevoerd. Hierbij moet uiteraard wel bedacht worden dat de IAD als verbijzonderd element van interne controle aan het management van de organisatie rapporteert. Hierbij wordt een rechtstreekse communicatielijn verondersteld tussen de IAD en de RvC. Uiteraard neemt de $\mathrm{RvC}$ ook kennis van constateringen van externe accountants op het vlak van de werking van de interne beheersomgeving zoals deze meestal in de management letter zijn opgenomen.

c. Het stimuleren van een onafhankelijk gepositioneerde rapportagelijn inzake ongewenste afwijkingen die zich binnen de interne beheersingsomgeving voordoen (een zogenaamde whistle blowerregeling).

De Association of Certified Fraud Examiners (ACFE, 2010) adviseert om in combinatie hiermee medewerkers te trainen in:

a. wat fraude is;

b. hoe fraude iedereen in de organisatie raakt;

c. hoe te rapporteren over zaken die het daglicht mogelijk niet verdragen kunnen.

Het blijkt namelijk dat maar liefst 47 procent van alle fraudes ontdekt wordt op basis van tips van eigen medewerkers. Daarmee zijn eigen medewerkers verreweg het meest effectieve instrument om fraude te ontdekken.

Daarnaast dient de RvC kennis te nemen van de meldingen die zijn binnengekomen in het kader van deze zogenaamde klokkenluidersregeling en desgewenst rechtstreeks in contact te treden met de klokkenluider.

Er blijft vervolgens voor de RvC dan nog één vraag over. Het management is als eindverantwoordelijke voor de interne beheersingsomgeving in staat om de binnen de organisatie aangebrachte functiescheidingen te doorbreken en de rapportages inzake het functioneren van de interne beheersingsomgeving aan te laten passen. $\mathrm{De} \mathrm{RvC}$ zal zichzelf de vraag moeten stellen of een dergelijke aanpassing (veelal in combinatie met het manipuleren van de resultaten van de organisatie) door het management wel of niet heeft plaatsgevonden.

Het lijkt verstandig indien de $\mathrm{RvC}$ eenmaal per jaar in een vergadering brainstormt over de vraag welke frauderisico's te onderkennen zijn. Dit stimuleert tevens het handhaven van een professioneel kritische houding tegenover de door het management gepresenteerde cijfers.

Het ligt daarbij voor de hand dat in situaties waarbij het management hoge bonussen ontvangt bij het behalen van de gestelde doelen er een groter belang voor het management is om de rapportages te beïnvloeden dan wanneer dit niet het geval is. Een vergelijkbare situatie geldt bij het bezit van optie- of aandelenpakketten door het management.

Uit al deze eigen maatregelen en de gesprekken met het management zal de $\mathrm{RvC}$ een beeld destilleren ten aanzien van de interne beheersingsomgeving. Uiteraard doet zich een probleem voor indien dit geen goed gevoel bij de $\mathrm{RvC}$ oplevert. De $\mathrm{RvC}$ zal in een dergelijke situatie in eerste instantie tot nader onderzoek besluiten. Desgewenst kan de $\mathrm{RvC}$ besluiten hiervoor een externe accountant in te huren.

Leveren bovengenoemde maatregelen een onbevredigend resultaat op dan rest de $\mathrm{RvC}$ slechts als optie vanuit haar verantwoordelijkheid als toezichthouder in te grijpen.

\section{Samenvatting en discussie}

In dit artikel is een verkenning uitgevoerd naar de rol van de $\mathrm{RvC}$ bij het beoordelen van de interne beheersingsomgeving. Daartoe is geconcludeerd dat de $\mathrm{RvC}$ toezicht houdt op het bestuur (de agent) ten behoeve van de stakeholders (principalen). De code Tabaksblat en de Amerikaanse regelgeving geven geen aanwijzingen aan commissarissen hoe de interne beheersingsomgeving te toetsen. Zowel de Nederlandse als de Amerikaanse regelgeving voorkomen derhalve niet de schandalen zoals die zich in het verleden hebben voorgedaan bij Enron, Worldcom en Satyam.

Indien commissarissen niet op structurele wijze kennis nemen van de werking van de interne beheersingsomgeving bestaat er onvoldoende inzicht in de risico's dat onbetrouwbare informatie wordt verstrekt.

Het artikel geeft daarom aan welke maatregelen commissarissen uit kunnen voeren om de goede werking van de interne beheersingsomgeving te toetsen.

Aangezien er nog relatief weinig bekend is over de rol van het management en toezichthouders in relatie tot de interne beheersingsomgeving lijk het in het verlengde van 
dit artikel goed nader empirisch onderzoek te doen naar een drietal gerelateerde vragen:

a. Stelt het management zelf de goede werking van de interne beheersingsomgeving vast? Zo ja op welke wijze doen zij dit?

b. Welke werkzaamheden verrichten toezichthouders ter toetsing hierop? Zijn deze werkzaamheden voldoende?

c. Op welke wijze rapporteren de commissarissen over de door hen op dit vlak uitgevoerde werkzaamheden?
Prof. dr O.C. van Leeuwen is hoogleraar Bestuurlijke

Informatieverzorging aan de Vrije Universiteit van

Amsterdam en tevens werkzaam als Executive Vice

President bij Atos Consulting. Prof. dr P. Wallage is

hoogleraar Accountantscontrole aan de Vrije Universiteit

van Amsterdam en Universiteit van Amsterdam en tevens

als partner werkzaam bij KPMG.

\section{Noten}

$\mathbf{1}$ In de Structuurregeling is aangegeven dat een RvC verplicht is als de onderneming voldoet aan de volgende voorwaarden:

een eigen vermogen van $€ 16$ miljoen of meer; de rechtspersoon krachtens wettelijke verplichting een OR heeft ingesteld;

bij de rechtspersoon tenminste 100 werknemers in Nederland werkzaam zijn.

De Code Tabaksblat gaat ervan uit dat er toezicht wordt ingesteld: in de Code wordt uitgegaan van een stelsel waarin naast het bestuur een afzonderlijke RvC functioneert, maar wordt ruimte gelaten voor een afwijkende regeling (comply or explain). Bij vrijwel alle Nederlandse beursvennootschappen is voorzien in een raad van commissarissen of een andere vorm van intern toezicht.

2 Zo waren Bernie Ebbers en Scott Sullivan, resp. de CEO en CFO van WorldCom persoonlijk betrokken bij het maken van journaalposten om het resultaat frauduleus te verhogen (Cooper, 2008)

3 Moral hazard is een economisch begrip dat verwijst naar veranderingen in het gedrag van partijen indien zij niet direct risico lopen voor hun daden. Dit kunnen economische agenten zijn waardoor moral hazard samenhangt met principaal-agentproblematiek.

Een voorbeeld van moral hazard is dat verzekerden over het algemeen eerder bereid zijn om risico te lopen, dan onverzekerden die eventuele schade voor eigen rekening moeten nemen. lemand zal bijvoorbeeld minder geneigd zijn op zijn auto te passen, omdat hij toch tegen schade en diefstal verzekerd is. Moral hazard kan op twee manieren voorkomen. Het kan zich voordoen met betrekking tot het ontstaan van de schade zelf (het eerder genoemde voorbeeld van de auto), maar het kan er ook toe leiden dat men geleden schade sneller gaat claimen.
4. Men neemt soms wel aan dat de raad van commissarissen het vertegenwoordigende lichaam van de aandeelhouders is, zodat deze een vinger aan de pols van de raad van bestuur kunnen houden. Dit is strikt genomen niet juist aangezien de raad van commissarissen te allen tijde in het belang van de vennootschap en de onderneming moet handelen, zonder opdracht en onafhankelijk van bijkomstige belangen.

$\mathbf{5}$ De auteurs zijn zich uiteraard bewust van het verschil tussen de Amerikaanse one-tier en Nederlandse two-tier structuur. Naar de mening van de auteurs beïnvloedt dit echter niet de rol van de toezichthouder met betrekking tot interne beheersing. Overigens beslist de Eerste Kamer deze zomer over een wet die het one-tier systeem in Nederland mogelijk moet maken.

6 Redelijke mate van zekerheid wordt door alle AEX en AMX fondsen verstrekt. Uitleg van niet toepassen wordt gegeven door één lokaal fonds. Een ander lokaal fonds past de bepaling niet toe. Van de 101 onderzochte fondsen gaven 95 fondsen een verklaring af bij het functioneren in 2009. Twee lokale fondsen leggen uit waarom geen verklaring is afgegeven terwijl 2 small caps en 2 lokale fondsen de bepaling niet toepassen. Van de 101 onderzochte fondsen geeft het bestuur van 96 fondsen een onderbouwing. Eén lokaal fonds legt uit waarom geen naleving heeft plaatsgevonden. Eén small cap fonds en 3 lokale fondsen passen de bepaling niet toe (Commissie Corporate Governance, Monitoring Commissie, 2010, p. 22).

7 Kenmerkend verschil tussen accountant en commissaris is dat eerstgenoemde een oordeel uitspreekt maar geen directe verantwoordelijkheid draagt voor het nemen van vervolgactie respectievelijk sanctionering.
8 De commissarissen van de NV worden op voordracht van de raad van commissarissen benoemd door de algemene vergadering. De algemene vergadering en de centrale ondernemingsraad kunnen personen voor benoeming tot commissaris aanbevelen. Voor een derde van het aantal leden van de raad van commissarissen geldt dat de raad van commissarissen een door de centrale ondernemingsraad aanbevolen persoon op de voordracht plaatst tenzij de raad van commissarissen bezwaar maakt tegen de aanbeveling (BW 2, artikel 158)

9. Minimaal één lid van de raad van commissarissen is een zogenoemde financieel expert, hetgeen inhoudt dat deze persoon relevante kennis en ervaring heeft opgedaan op financieel administratief/accounting gebied bij beursvennootschappen of bij andere grote rechtspersonen. 10 Overige taken die door Tabaksblat (2003) genoemd worden zijn:

c) de naleving van aanbevelingen en opvolging van opmerkingen van in- en externe accountants; d) de rol en het functioneren van de interne audit functie;

e) het beleid van de vennootschap met betrekking tot tax planning;

f) de relatie met de externe accountant waaronder in het bijzonder zijn onafhankelijkheid, de bezoldiging en eventuele niet-controlewerkzaamheden voor de vennootschap;

g) de financiering van de vennootschap; en h) de toepassingen van de informatie- en communicatietechnologie.

11 In 2011 is een project gestart om het COSO-raamwerk Internal Control an Integrated Framework te herzien. Er worden echter geen fundamentele wijzigingen verwacht (COSO News Release November 18, 2010). 


\section{Literatuur}

Association of Certified Fraud Examiners (2010), Report to the nations on occupational fraud and abuse, global fraud study, Austin, USA; zie: www.acfe.com/rttn/2010-rttn.asp. - American Institute of Certified Public Accountants (AICPA) (2005), Management override of internal controls: The Achilles heel of fraud prevention, The Audit Committee and Oversight of Financial Reporting; zie: www. aicpa.org.

- Beasley, M.S., J.V. Carcello, D.R. Hermanson en T.L. Neal (2010), Fraudulent financial reporting 1998 - 2007, Committee of Sponsoring Organizations of the Treadway Commission (COSO); http://www.coso.org/ FraudReport.htm.

- Commissie Corporate Governance (2003/ 2008), De Nederlandse Corporate Governance Code, Code Tabaksblat, 2003 en 2008; zie www.commissiecorporategovernance.nl. - Commissie Corporate Governance, Monitoring Commissie Corporate Governance (MC), Tweede rapport over de naleving van de Nederlandse Corporate Governance Code; zie www. commissiecorporategovernance.nl.
Committee of Sponsoring Organizations (COSO) (1987), Report of the National Commission on Fraudulent Financial Reporting; zie: www.coso.org. - Committee of Sponsoring Organizations (COSO) (1992, 1994), Internal Control Integrated Framework; zie: www.coso.org. - Cooper, C. (2008), Extraordinary circumstances: The journey of a corporate whistleblower, John Wiley.

口 Dassen, R.J.M. (1989), De leer van het gewekte vertrouwen: agency avant la lettre? Maandblad voor Accountancy en Bedrijfseconomie, vol. 63, no. 9, pp. 341-352. - Hunton, J.E., R. Hoitash en J.C. Thibodeau (2011), The relationship between tone at the top and earnings quality, available at: http://ssrn. com/abstract $=1609709$.

- International Federation of Accountants (IFAC) (2003), Rebuilding public confidence in financial reporting, An international perspective, NY; zie: www.ffac.org.
Peecher, M.E., R. Schwartz en I. Solomon (2007), It's all about audit quality: Perspectives on strategic-systems auditing, Accounting, Organizations and Society, vol. 32, no. 4-5, pp. 463-485.

Raju, Ramalinga, (2009), Letter to the Board of Satyam Computer Services Ltd., January 7, zie: http://trak.in/tags/business/2009/01/06 /satyam-head-raju-admits-fraud-letter-boarddirectors/.

- Securities and Exchange Commission (SEC) (2007), Commission Guidance Regarding Management's Report on ICFR Under Section 13(a) or 15(d) of the Securities Exchange Act of 1934; zie: www.sec.gov.

- Van Leeuwen, O.C. en Ph. Wallage (2010), Het evalueren van de interne beheersomgeving een onderbelicht thema, Maandblad voor Accountancy en Bedrijfseconomie, vol. 84, no. 9, pp. 447-457.

Wallage, Ph. (1993), Auditing theory, Handboek Accountancy, Samsom Bedrijfsinformatie, Alphen aan den Rijn, 13. 